Proceedings of the 11th Polish-Japanese Joint Seminar on Micro and Nano Analysis, Gniew, September 11-14, 2016

\title{
Modification of Microstructure and Properties of Extruded Mg-Li-Al Alloys of $\alpha$ and $\alpha+\beta$ Phase Composition using ECAP Processing
}

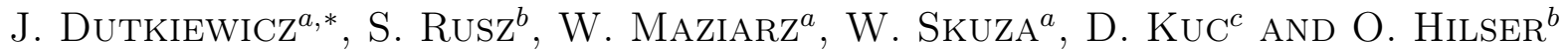 \\ ${ }^{a}$ Institute of Metallurgy and Materials Science, Polish Academy of Sciences, \\ W.S. Reymonta 25, 30-059 Kraków, Poland \\ ${ }^{b}$ Technical University Ostrava, Department of Mechanical Engineering, 17 Listopadu 15, Ostrava, Czech Republic \\ ${ }^{c}$ Silesian Technical University, Department of Metallurgy and Materials Science, \\ Z. Krasińskiego 8, 40-019 Katowice, Poland
}

\begin{abstract}
Two magnesium based alloys containing $4.5 \mathrm{wt} \% \mathrm{Li}$ and $1.5 \mathrm{wt} \% \mathrm{Al}$ (alloy 1) and $9 \mathrm{wt} \% \mathrm{Li}$ and $1.5 \mathrm{wt} \%$ $\mathrm{Al}$ (alloy 2) were cast under argon atmosphere and hot extruded at $350{ }^{\circ} \mathrm{C}$. Microstructure of alloy 1 consisted of hexagonal $\alpha$ phase of average grain size $20 \mu \mathrm{m}$ and small aluminum rich precipitates being the most probably $\mathrm{AlLi}_{2} \mathrm{Mg}$ phase. Alloy 2 in the extruded form consisted of lamellas of $\alpha+\beta$ phases of thickness $5-20 \mu \mathrm{m}$ and length above $100 \mu \mathrm{m}$. Significant grain refinement down to about $2 \mu \mathrm{m}$ was observed in one-phase hexagonal (hcp) alloy 1 after one pass of ECAP processing with helical component. Two-phase (hcp + bcc) alloy 2 showed higher non-homogeneity after the first equal channel angular pressing pass due to easier deformation of softer bcc phase, while both, $\alpha$ and $\beta$ phases exhibited low angle grain boundaries. The hardness and the yield strength of the alloys were higher for alloy 1 ( $68 \mathrm{HV}$ and $205 \mathrm{MPa}$, respectively) than those of alloy 2 (61 HV and $175 \mathrm{MPa}$ ). Subsequent equal channel angular pressing passes were performed at lower extrusion stress. The hardness of both alloys did not change significantly after subsequent equal channel angular pressing passes and revealed tendency to decrease. Two-phase alloy showed superplastic properties already after one equal channel angular pressing pass at $160^{\circ} \mathrm{C}$ with grain growth after superplastic tensile testing. Single phase hcp alloy did not show such properties after 1 pass, but after a few equal channel angular pressing passes it could be superplastically formed.
\end{abstract}

DOI: $10.12693 /$ APhysPolA.131.1303

PACS/topics: 83.50.-v, 81.40.Lm, 81.20.Fw

\section{Introduction}

$\mathrm{Mg}-\mathrm{Li}$ alloys are the lightest structural materials with a high specific strength and stiffness, good magnetic screening, and shock resistance ability. Precipitates and solute atoms are expected to be the main obstacles for dislocation motion at lower temperatures in hexagonal $\alpha$ type alloys. Cross slip causing stress drop with increasing temperature is presumably the dominant thermally activated mechanism at higher temperatures [1]. The addition of aluminum and copper to the $\alpha$ or $\beta$ type $\mathrm{Mg}-\mathrm{Li}$ alloys brings about the significant improvement of the age hardening effect in the $\alpha$ phase, although a limited data concerning the structure of precipitates was given $[2,3]$. The magnesium- $8 \mathrm{wt} \%$ lithium alloy was reported in [4] to consist of hcp $(\alpha)$ and bcc $(\beta)$ phases, with the $\alpha$ phase appearing as plates in the $\beta$ matrix. A near Burgers orientation relationship was observed between the two phases, i.e., [0001] $\alpha \|[0-11] \beta$, and $(-100) \alpha \|(-211) \beta$. Two-phase $\mathrm{Mg}-\mathrm{Li}-\mathrm{Al}$ alloy processed by conventional extrusion followed by equal channel angular pressing (ECAP) at room temperature (RT) showed that the grains of the $\beta$ phase matrix were sub-

*corresponding author; e-mail: stantially refined, with the mean size decreasing from $60 \mu \mathrm{m}$ to $200 \mathrm{~nm}[4,5]$. Additionally, the $\alpha$ precipitates, embedded in the $\beta$ grains and the ternary $\mathrm{MgLiAl}_{2}$ phase coexisting with the $\alpha$ precipitates were homogenized by ECAP processing. The significant grain refinement was reported in the cast $\mathrm{Mg}-8 \mathrm{wt} \% \mathrm{Li}$ alloy after ECAP at the temperature of $473 \mathrm{~K}$ [6]. Following extrusion and subsequent two passes of ECAP led to excellent superplastic properties, including the maximum elongation of $\approx 970 \%$ at $473 \mathrm{~K}$ at the strain rate of $1.0 \times 10^{-4} \mathrm{~s}^{-1}$. The strain rate sensitivities under the optimum superplastic conditions were measured as $m \approx 0.4-0.6$. The superplastic forming was also reported in ultrafinegrained $\mathrm{Mg}-9 \mathrm{Li}-$ 1Zn (LZ91) alloy sheets prepared through high-speedratio differential speed rolling (HRDSR) [7] giving in consequence the grains of $\alpha$ and $\beta$ phases reduced to the size of $\approx 1 \mu \mathrm{m}$. The HRDSRed alloy exhibited the enhanced strength and ductility at room temperature and excellent low temperature superplasticity in the temperature range $423-523 \mathrm{~K}$. The $\mathrm{Mg}-\mathrm{Li}$ alloy with $8 \mathrm{wt} \% \mathrm{Li}$ was processed by high-pressure torsion (HPT) to achieve ultrafine grains with the average grain size of $500 \mathrm{~nm}$. The alloy showed good superplastic properties at the strain rate of $10^{-3} \mathrm{~s}^{-1}$ starting at the temperature of $50^{\circ} \mathrm{C}$ or higher [8].

In the present paper the ECAP method combined with helical part in horizontal area of the channel was applied 
to increase the extrusion force applied in order to decrease the grain size of $\alpha$ and $\alpha+\beta$ grains. The changes of microstructure and mechanical properties were examined in alloys of either $\alpha$ or $\alpha+\beta$ phase composition. A small aluminum addition was applied to $\mathrm{MgLi}$ alloys in order to increase their mechanical properties and to study its effect on superplasticity in the single and two-phase alloys.

\section{Experimental procedure}

Two magnesium based alloys of compositions $4.5 \mathrm{wt} \% \mathrm{Li}$ and $1.5 \mathrm{wt} \% \mathrm{Al}$ (alloy 1) intended to contain the $\alpha$ phase (hcp) and $9 \mathrm{wt} \% \mathrm{Li}, 1.5 \mathrm{wt} \% \mathrm{Al}$ (alloy 2) intended to be composed of $\alpha+\beta$ (hcp + bcc) phases were cast under argon atmosphere and extruded at $350{ }^{\circ} \mathrm{C}$ to obtain bars of cross-section $12 \times 12 \mathrm{~mm}^{2}$ suitable for the ECAP deformation. The ECAP tool consisted of helical part in the horizontal area of the channel with the angle of lead $\gamma=30^{\circ}$. The basic aim of the use of helix consisted in the simulation of back pressure and thus in the increase of extrusion force. Up to 3 ECAP passes were applied using rotation of samples in the subsequent passes. The extrusion force was measured during the process. The hardness of samples was tested using a Zwick ZHU 250 instrument in the Vickers method and the tensile tests were performed applying an Instron 6025 testing machine at room and elevated temperatures using samples of thickness $2 \mathrm{~mm}$ and width $3.5 \mathrm{~mm}$, testing length $18 \mathrm{~mm}$ and total length $45 \mathrm{~mm}$ cut out after ECAP by an electro-spark machine. The structure and composition were studied using a Philips CM20 or FEI Technai G6 transmission electron microscopes and Leica DM IRM optical microscope. Thin samples of hot pressed or ECAPed alloys were cut by electro spark device, then electropolished in electrolyte consisting of $750 \mathrm{ml}$ AR grade methanol, $150 \mathrm{ml}$ butoxyethanol, $16.74 \mathrm{~g}$ magnesium perchlorate and $7.95 \mathrm{~g}$ lithium chloride and finally dimpled using Gatan dimpler and ion beam thinned using Leica EM RES101 ion beam thinner. The X-ray diffraction was performed using a Philips PW 1710 diffractometer with Co $K_{\alpha}$ radiation.

\section{Results and discussion}

Figure 1 shows optical microstructures of extruded alloys 1 and 2 in the as extruded condition. One can see that the alloy 1 consists mostly of equiaxial hexagonal $\alpha$ grains of the average size of $60 \mu \mathrm{m}$. Based on X-ray diffraction, only hexagonal $\alpha$ grains were identified, although darker particles could be also seen, which the most probably resulted from the aluminum addition in the form of AlLi or $\mathrm{Mg}_{17} \mathrm{Al}_{12}$ phases as suggested in [1]. The formation of $\mathrm{MgLi}_{2} \mathrm{Al}$ particles was also suggested to appear at higher Li content [9]. The microstructure of alloy 2 consisted of two types of elongated grains of the $\alpha$ phase (bright color) and the $\beta$ phase (gray color), which were identified using X-ray diffraction as hexagonal $\alpha$ and bcc $\beta$ phase.

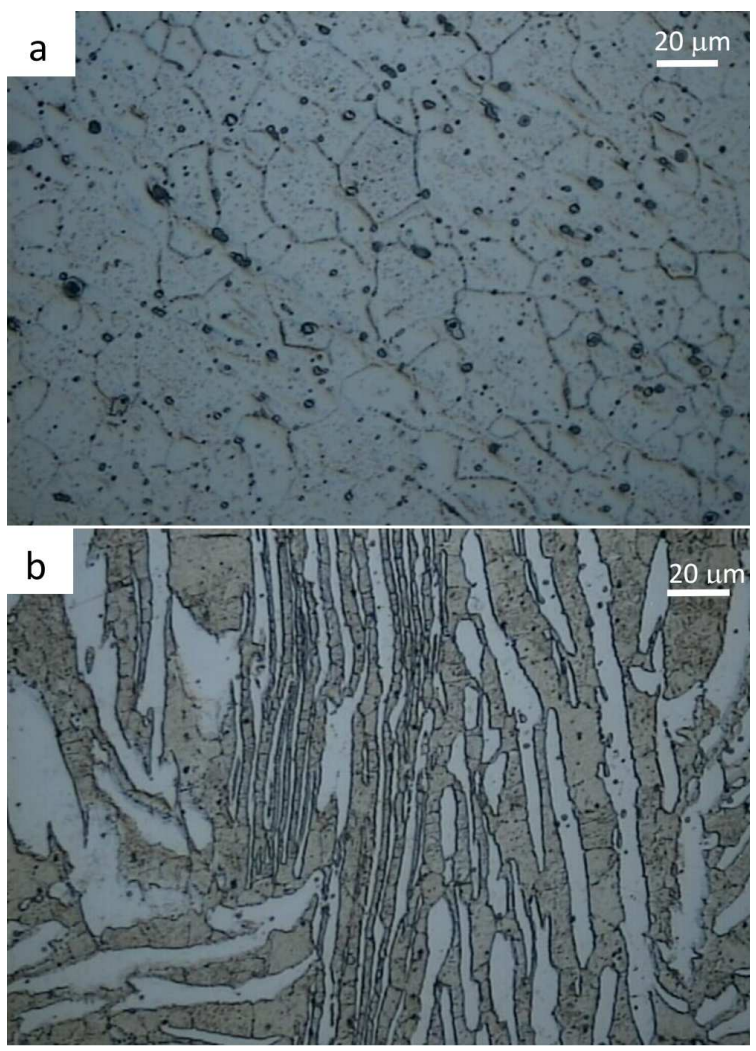

Fig. 1. Optical microstructures of as hot extruded at $350^{\circ}$ alloys 1 (a) and 2 (b)

It is obvious that the cellular dendritic-like $\alpha$ phase is uniformly dispersed within the $\beta$ phase matrix. The similar structure was observed in the two phase $\alpha+\beta$ alloy reported in $[4,6]$. Figure 2 shows the results of hardness measurements of the investigated alloys 1 and 2 in the as extruded state and after 1-3 ECAP passes processed at $250^{\circ} \mathrm{C}$ and $160^{\circ} \mathrm{C}$, respectively. One can see that in alloy 1 hardness decreases from $70 \mathrm{HV}$ to $60 \mathrm{HV}$ after the first pass, then slightly raises to $62 \mathrm{HV}$ and then decreases again, while in alloy 2 it decreases gradually from 61 to 60 after the first pass, then to $58 \mathrm{HV}$ after the second one and then stabilizes. In another work on twophase MgLiZn alloys, a slight increase of hardness was observed after HRDSR [7], however it might have been due to different deformation treatment leading to lower hardness $(50 \mathrm{HV})$. In the single phase hexagonal MgLi alloys hardening was reported to result from precipitates and work.

Figure 3 shows a photograph of samples after ECAP processing, in which their helical shape can be seen. The graph shows extrusion strain versus ECAP displacement during 1-3 passes. One can see that the flow stress at $250^{\circ} \mathrm{C}$ decreases with the following passes from about $130 \mathrm{MPa}$ for the first pass down to $100 \mathrm{MPa}$ after the third pass. It indicates most probably an increasing participation of grain boundary sliding with the subsequent passes. 


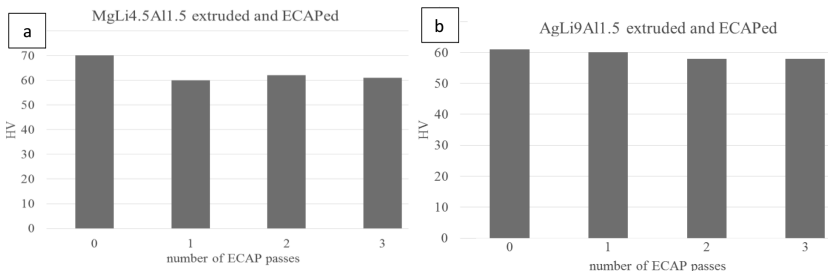

Fig. 2. Graphs showing (a) results of $\mathrm{HV}_{10}$ hardness measurements of alloy 1 (MgLi4.5Al1.5) after 0-3 ECAP passes at $250{ }^{\circ} \mathrm{C}$ and (b) results of $\mathrm{HV}_{10}$ hardness measurements of alloy 2 (MgLi9Al1.5) after 0-3 ECAP passes at $160^{\circ} \mathrm{C}$.

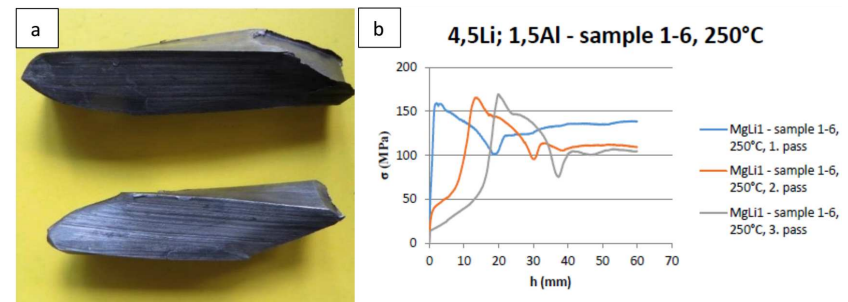

Fig. 3. (a) Samples of alloy 1 after 1 and 3 ECAP passes and (b) stress versus sample ECAP displacement relationship during 1-3 passes of extruded alloy during ECAP processing at $250^{\circ} \mathrm{C}$.

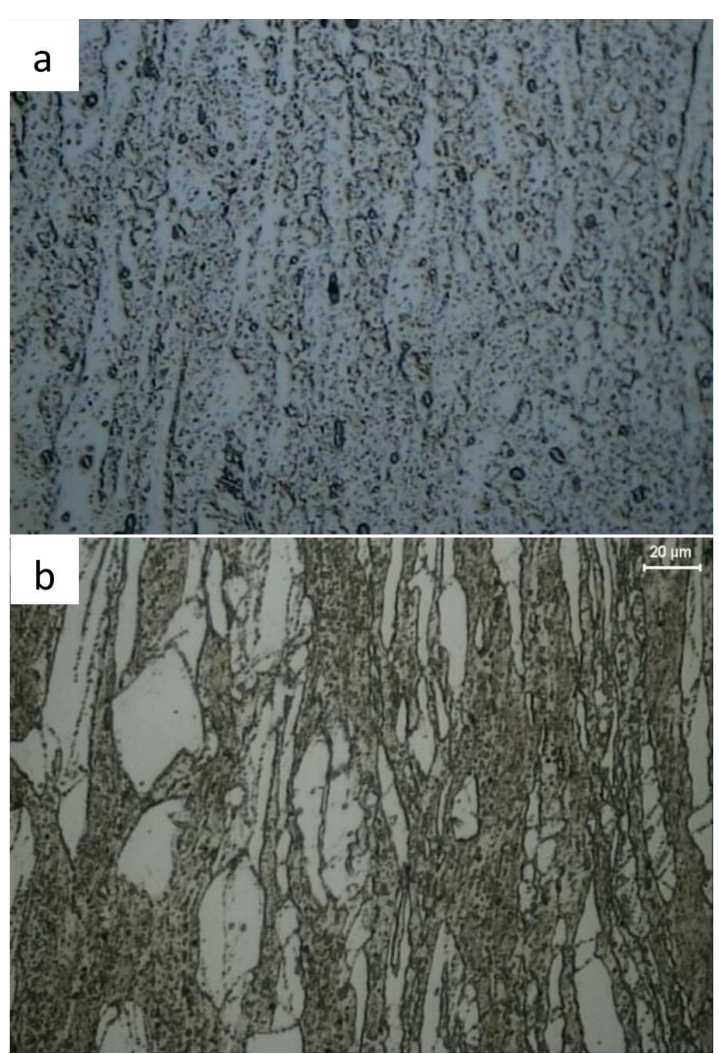

Fig. 4. Optical microstructures of as hot extruded at $350^{\circ}$ alloys 1 and 2 after 1 pass of ECAP processing at temperature of $250{ }^{\circ} \mathrm{C}$ (alloy $1,(\mathrm{a})$ ) and at $160{ }^{\circ} \mathrm{C}$ (alloy 2, (b)) showing grain elongation toward the ECAP pressing direction.
The optical microstructures after the first ECAP pass show a significant directionality of elongated and refined grains (Fig. 4a and b). In both alloys some nonhomogeneity of deformation can be seen, however it is larger in alloy 2. It seems that it is caused by lower strength of the bcc Li rich phase, which more easily undergoes deformation [6-10].

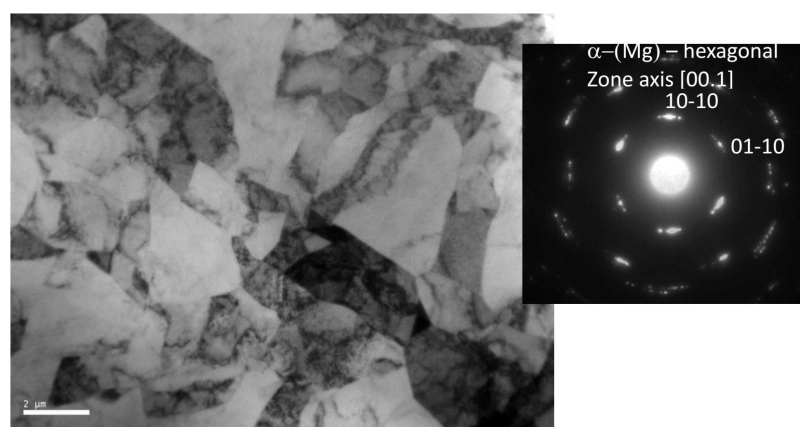

Fig. 5. TEM micrograph of alloy 1 after one pass of ECAP processing at $220^{\circ} \mathrm{C}$. Grain refinement with mostly low angle grain boundaries as results from the diffraction pattern reflections diffused along DebyeScherrer rings (inset) can be observed.

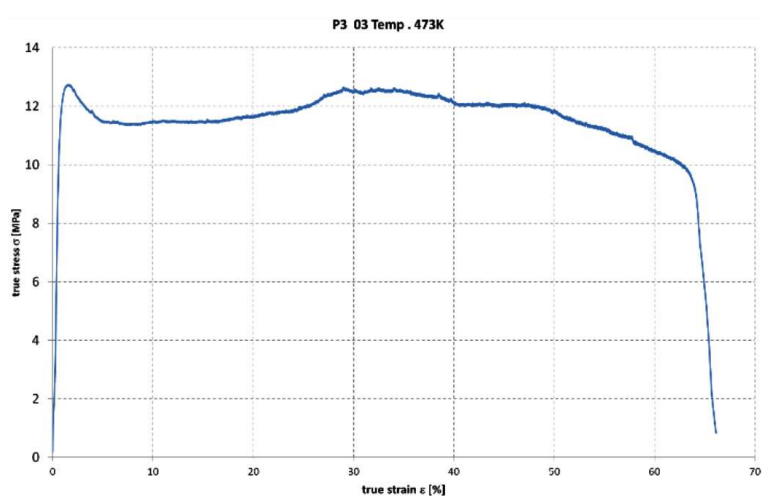

Fig. 6. Tensile test performed at $200^{\circ} \mathrm{C}$ at rate $10^{-4} \mathrm{~s}^{-1}$ using sample cut from alloy 2 after 1 ECAP pass at $160^{\circ} \mathrm{C}$. One can see deformation at low, almost constant stress of $12 \mathrm{MPa}$ and elongation approaching $70 \%$, indicating superplastic deformation.

TEM microstructure of alloy 1 after the first pass is shown at a relatively low magnification; softening is connected with cross slip and the dislocation climb process [10] which may be a reason for small deformation hardening (Fig. 5). It can be seen that fine grains of the average size near $2 \mu \mathrm{m}$ do not contain directionality, which was typical for the initial grains. The diffraction pattern from the visible area shows basically the same orientation of zone axis [0001].

The reflections from the hexagonal $\alpha$ phase are diffused along the Debye-Scherrer rings indicating a low angle misorientation between subgrains formed during the first pass of ECAP processing. The tensile test performed 
at rate $10^{-4} \mathrm{~s}^{-1}$ and the same temperature of $160^{\circ} \mathrm{C}$ like ECAP was performed, showed a high elongation near $70 \%$ which was lower than that observed for other superplastic two phase MgLi alloys [6, 7, 10]. However, the sample after HPT carried out at lower temperature showed significantly better superplastic properties after ECAP than the other alloys [10]. On the other hand, the method has limitations concerning the size of samples and inhomogeneity of deformation. The single phase hexagonal alloy 1 after an ECAP pass at $220^{\circ} \mathrm{C}$ showed elongation only slightly better than that of ECAP processed at room temperature. Moreover, a higher number of ECAP passes was needed to induce superplasticity, which was easily attainable in two phase alloys after only 1 ECAP pass, as shown in Fig. 6.

\section{Conclusions}

- One pass of ECAP deformation with a helical component led to significant grain refinement down to about $2 \mu \mathrm{m}$ in hexagonal (hcp) single phase and two $($ hcp $=$ bcc $)$ phase alloys. Two phase alloy 2 showed higher non-homogeneity due to easier deformation of softer bcc phase, while both alloys exhibited low angle grain boundaries after ECAP. Subsequent ECAP passes could be performed at lower extrusion stresses. The hardness of both alloys did not change significantly after ECAP passes and revealed tendency to decrease.

- Two phase alloy showed superplastic properties already after one ECAP pass at $160^{\circ} \mathrm{C}$ showing grain growth after superplastic tensile testing. Single phase (hcp) alloy did not show such properties after 1 pass, but after a few ECAP passes it could be superplastically formed.

\section{Acknowledgments}

The financial support of National Science Center $\mathrm{NCN}$ in the frame of the OPUS research project No.2014/15/B/ST8/03184 is gratefully acknowledged.

\section{References}

[1] Z. Drozd, Z. Trojanová, S. Kúdela, J. Alloys Comp. 378, 192 (2004).

[2] G.H. Park, J.T. Kim, H.J. Park, Y.S. Kim, H.J. Jeong, N. Lee, Y. Seo, J.Y. Suh, H.T. Son, W.M. Wang, J.M. Park, K.B. Kim, J. Alloys Comp. 680, 116 (2016)

[3] N. Saito, M. Mabuchi, M. Nakanishi, K. Kubota, K. Higashi, Scr. Mater. 36, 551 (1997).

[4] M.V. Kral, B.C. Muddle, J.F. Nie, Mater. Sci. Eng. A 460-461, 227 (2007).

[5] T. Liu, S.D. Wu, S.X. Li, P.J. Li, Mater. Sci. Eng. A 460-461, 499 (2007).

[6] M. Furui, Ch. Xu, T. Aida, M. Inoue, H. Anada, T.G. Langdon, Mater. Sci. Eng. A 410-411, 439 (2005).

[7] W.J. Kim, M.J. Kim, J.Y. Wang, Mater. Sci. Eng. A 516, 17 (2009).

[8] H. Matsunoshita, K. Edalati, M. Furui, Z. Horita, Mater. Sci. Eng. A 640, 443 (2015).

[9] J. Zhang, Yang Zhang, G. Wu, W. Liu, L. Zhang, W. Ding, Mater. Sci. Eng. A 621, 198 (2015).

[10] Z. Trojanova, Z. Drozd, P. Lukac, F. Chmelik, Mater. Sci. Eng. A 410-411, 148 (2005). 